\title{
A Comparative Study of Various Compendial Biuret Methods for Estimation of Protein in Human Biologicals
}

\author{
CHARU ARORA, A. PRAKASH, J. P. PRASAD, Y. MADHU, SUDHA V. GOPINATH, S. SINGH, P. KUMAR, ANKITA SINGH, \\ A. KUMAR AND V. SINGH* \\ National Institute of Biologicals, Noida-201 309, India
}

Arora et al.: Comparison between Various Compendial Biuret Methods

\begin{abstract}
Blood products laboratory is a Central Drug Testing Laboratory for testing quality standards of plasmaderived products in India. Blood products laboratory received 243 batches of human normal albumin during the financial year 2015-16 from indigenous and international manufacturers for testing. As per Indian Pharmacopoeia, the biuret method is different from European and British Pharmacopoeia for protein estimation, therefore, harmonisation of such method is necessary as per World Health Organization's recommendation. In this context, blood products laboratory conducted a comparative study between the methods of Indian, European and British Pharmacopoeia for protein estimation in biologicals, especially for human albumin preparation to prevent any bias regarding protein content between indigenous samples and imported products. Results showed that both the methods were significantly not different $(p=0.05)$, and also showed that Indian Pharmacopoeial biuret method was more sensitive although reagent stability was lower than that of European and British Pharmacopoeial methods.
\end{abstract}

Key words: Biuret method, Indian Pharmacopoeia, European Pharmacopoeia, British Pharmacopoeia, World Health Organization, methods harmonization

Compendial methods are considered as statutory for the local manufacturers, controllers and other stakeholders for ensuring quality control of pharmaceutical and biological preparations ${ }^{[1]}$. World Health Organization (WHO) promotes harmonized and suitable quality control testing standards among all stakeholders of
WHO with the aim to facilitate analytical methods, which can be reproduced with suggested equipment at primary pharmaceutical quality control laboratories ${ }^{[2]}$. National Institute of Biologicals (NIB) is an autonomous Institution under the Ministry of Health and Family Welfare, Government of India, established in January 
1992. NIB acts as a National Control Laboratory for assessing and assuring the availability of standard and quality biological products both indigenous and imported. Blood Products Laboratory (BPL) of NIB is a Gazette-notified Central Drug testing laboratory for testing of seven plasma-derived products, namely human albumin (HA), human normal immunoglobulin, human coagulation factor VIII, human coagulation factor IX, plasma protein fractionation, fibrin sealant kit, and antiinhibitor coagulation complex ${ }^{[3]}$.

Human plasma is a source of important medicinal products, which is obtained by a combination of largescale processing steps known as "fractionation". It is important that these products have an appropriate quality and safety profile. Plasma-derived products are regarded as medicinal products worldwide and their marketing authorization, which involves the official approval of the production process and quality assurance system. Central Drug Standard Control Organisation (CDSCO), New Delhi has the duty to enforce regulations for quality and safety of biological products in India.

HA is a major plasma-derived product produced during plasma fractionation. Protein concentration is one of the paramount quality control testing parameter for HA. BPL received HA for testing from the indigenous manufacturerorimported samples. Most of the importers follow biuret method for estimation of total protein, but Indian Pharmacopoeia 2014 (IP 2014) prescribes the Kjeldahl method for estimation of total protein in HA. Moreover, biuret method for the protein estimation mentioned in chapter 2.3.49, IP $2014^{[4]}$ is quite different compared to the method recommended in British Pharmacopoeia (BP) ${ }^{[5]}$ and European Pharmacopoeia $(E P)^{[6]}$. Since BP and EP are already harmonised with each other and following the same method. BPL conducted a literature review by using different online electronic tools like PubMed for any comparative or harmonised study conducted, but supportive data is not available. Therefore, BPL conducted the present study to evaluate the various pharmacopoeial biuret methods and their performance comparison for plasma-derived product HA preparation and to evaluate comparative differences and resemblance based upon analytical data and possibility of harmonisation of biuret method in IP (2014) with other international compendia biuret method.
Total ten batches of HA S1-S10 (five each of 5.0 and $20.0 \%$ stated value) were randomly selected for the study, each sample was analysed ten times in duplicate. Sigma-Aldrich protein standard bovine serum albumin $20 \%$ (Lot no SLBG8533V) was used to plot a standard graph (serial dilution of 2.0 to $10 \mathrm{mg} / \mathrm{ml}$ ).

Reagents of biuret methods for BP and EP were prepared as described in BP and EP Pharmacopoeia section 2.5.33, in brief, $3.46 \mathrm{~g}$ of copper sulphate was dissolved in $10 \mathrm{ml}$ of warm distilled water and labelled as reagent 1 , then $34.6 \mathrm{~g}$ of sodium citrate and $20.0 \mathrm{~g}$ of anhydrous sodium carbonate were dissolved in $80 \mathrm{ml}$ of warm distilled water and labelled as reagent 2, both the reagents were mixed, allowed to cool, and make up to $200 \mathrm{ml}$ with distilled water, labelled the reagent as Biuret reagent. Two millilitres of $0.5 \%$ test solution or $2.0 \mathrm{ml}$ normal saline in case of blank $(0.9 \% \mathrm{NaCl})$ was taken, and an equal volume $(2.0 \mathrm{ml})$ of $6.0 \%$ sodium hydroxide solution and $0.8 \mathrm{ml}$ biuret reagent were added, mixed, and incubated at room temperature $\left(25^{\circ}\right)$ for $30 \mathrm{~min}$; the absorbance at $545 \mathrm{~nm}$ was determined against blank by using UV/Vis spectrophotometer (Varian) and data were acquired through Cary WinUV software. Standard curve was plotted over a suitable range of standards situated between 1.0 and $8.0 \mathrm{mg} / \mathrm{ml}$.

Biuret reagent as per IP, 6.0 g sodium potassium tartrate and $1.5 \mathrm{~g}$ of cupric sulphate were dissolved in $500 \mathrm{ml}$ distilled water, $300 \mathrm{ml}$ of $10 \%$ sodium hydroxide and $5 \mathrm{~g}$ of potassium iodide were added and make it $1000 \mathrm{ml}$ with distilled water and labelled as biuret reagent. To $1.0 \mathrm{ml} 0.5 \%$ test solution, $4.0 \mathrm{ml}$ of biuret reagent was added, mixed and incubated at room temperature for $30 \mathrm{~min}$, absorbance at $550 \mathrm{~nm}$ was determined against blank and standard curve was plotted for the calculation of test solution. Method validation parameters were evaluated as per ICH Q2(R1) and quality control policy of NIB as described previously ${ }^{[7,8]}$ and all the results were statistically evaluated by using GraphPad Prism 7.0, followed by the student t-test. Significance was considered at $\mathrm{p}<0.05$ level as shown in Table 1 .

This is an open access article distributed under the terms of the Creative Commons Attribution-NonCommercial-ShareAlike 3.0 License, which allows others to remix, tweak, and build upon the work non-commercially, as long as the author is credited and the new creations are licensed under the identical terms

Accepted 09 July 2018

Revised 11 Novemebr 2017

Received 24 February 2017 Indian J Pharm Sci 2018;80(5):946-949 
Results suggested that both the methods were precise and accurate and results were comparable with each other showing no significant difference with each other for the estimation of total protein in HA at $5.0 \mathrm{mg} / \mathrm{ml}$ concentration levels. However, further analysis of both methods for limit of detection (LOD) and limit of quantification (LOQ) by standard deviation of the response and the slope method showed that biuret method as IP is more sensitive compared to $\mathrm{BP} / \mathrm{EP}$ as LOD and LOQ for the IP method were 0.0333 and 0.1011 and for the BP/EP method were 0.1194, 0.3619 , respectively (Table 2 ). This could be due to sodium potassium tartrate, which helps to stabilise the cupric ions in low alkaline medium and also enhance the reaction sensitivity, further an increase in sodium hydroxide might have led to increasing in turbidity ${ }^{[6]}$.

The IP 2014 method simpler and easier to perform due to single working reagent but stability of the reagent was lower at room temperature as per the observations made. A study conducted to evaluate the stability of reagent at room temperature $\left(25^{\circ} \pm 1\right)$ for six months by visual inspection for any turbidity or precipitation in the reagent. Results suggested that IP biuret reagent was stable up to $15 \mathrm{~d}$ compared to the biuret reagent of
$\mathrm{EP} / \mathrm{BP}$, which was found to be stable upto $6 \mathrm{mo}$, this could be due to an addition of sodium hydroxide and sodium potassium tartrate with cupric sulphate, which reduced the stability and led to precipitation of $\mathrm{Cu}^{2+}$ ions in the reagents. During establishment of the IP method in BPL, it was observed that in the IP chapter 2.3.49, standard preparations listed were in the range of 1.0$5.0 \mathrm{mg} / \mathrm{ml}$ and prescribed concentration of the test solution must be $5 \mathrm{mg} / \mathrm{ml}$, this is against the standard practice of good analytical procedure that the test solution concentration should fall in the middle of the standard curve and not on the extreme end of the curve. This problem could be easily avoided by plotting reference standard upto 8.0 or $10.0 \mathrm{mg} / \mathrm{ml}$ as shown in fig 1 . In conclusion, both biuret methods of IP and EP/BP were accurate and precise for the estimation of proteins in blood derived biological products, IP method was more sensitive and easy due single working reagent, on the other hand, BP/EP method has better reagent stability, which reduced the batch to batch variation. Research Institutes or National Regulatory laboratories could use any method or alternative for each other as both the methods were found to be totally in harmony with each other.

TABLE 1: COMPARISON OF PROTEIN CONTENTS IN HUMAN ALBUMIN PREPARATION ESTIMATED USING IP BIURET METHOD AND EP/BP METHOD

\begin{tabular}{|c|c|c|c|c|c|c|c|c|}
\hline \multirow{2}{*}{ Batch No } & \multicolumn{4}{|c|}{ Indian Pharmacopoeial (IP) biuret method } & \multicolumn{4}{|c|}{$\begin{array}{c}\text { European Pharmacopoeia (EP)/British } \\
\text { Pharmacopoeial (BP) method }\end{array}$} \\
\hline & Mean & SD & \% RSD & SEM & Mean & SD & \% RSD & SEM \\
\hline S1 & 20.15 & 0.151 & 0.749 & 0.048 & $20.075^{\mathrm{NS}}$ & 0.169 & 0.841 & 0.053 \\
\hline S2 & 20.1 & 0.183 & 0.908 & 0.058 & $20.025^{\mathrm{NS}}$ & 0.072 & 0.358 & 0.023 \\
\hline S3 & 20.04 & 0.099 & 0.496 & 0.031 & $20.045^{\mathrm{NS}}$ & 0.214 & 1.07 & 0.068 \\
\hline S4 & 19.965 & 0.175 & 0.876 & 0.055 & $20.031^{\mathrm{NS}}$ & 0.065 & 0.326 & 0.021 \\
\hline S5 & 19.96 & 0.356 & 1.782 & 0.112 & $20.042^{\mathrm{NS}}$ & 0.069 & 0.344 & 0.022 \\
\hline S6 & 5.03 & 0.064 & 1.273 & 0.021 & $5.020^{\mathrm{NS}}$ & 0.084 & 1.679 & 0.028 \\
\hline S7 & 5.049 & 0.059 & 1.177 & 0.02 & $5.045^{\mathrm{NS}}$ & 0.042 & 0.823 & 0.014 \\
\hline S8 & 5.083 & 0.047 & 0.931 & 0.016 & $5.031^{\mathrm{NS}}$ & 0.039 & 0.782 & 0.013 \\
\hline S9 & 5.015 & 0.055 & 1.097 & 0.018 & $5.025^{\mathrm{NS}}$ & 0.064 & 1.278 & 0.021 \\
\hline $\mathrm{S} 10$ & 5.035 & 0.059 & 1.179 & 0.02 & $5.020^{\mathrm{NS}}$ & 0.071 & 1.423 & 0.024 \\
\hline
\end{tabular}

Values are shown as mean $(n=10)$, Standard deviation, standard error of mean and \% RSD for each batch. NS is Non-significant

TABLE 2: DETECTION LIMIT AND QUANTITATION LIMIT CALCULATED USING SPECIFIC STANDARD CURVE FOR IP BIURET METHOD AND EP/BP METHOD

\begin{tabular}{lcc}
\hline Parameter & IP biuret method $(\mathrm{n}=10)$ & EP/BP biuret method $(\mathrm{n}=10)$ \\
\hline Regression coefficient & $0.9997 \pm 0.0001$ & $0.9998 \pm 0.0002$ \\
Slope & $0.0997 \pm 0.0003$ & $0.1312 \pm 0.0072$ \\
Interception & $0.0093 \pm 0.0010$ & $0.0026 \pm 0.0047$ \\
LOD & 0.0333 & 0.1194 \\
LOQ & 0.1011 & 0.3619 \\
\hline
\end{tabular}

The detection limit (DL) and quantitation limit (QL) calculated as per ICH Q2 (R1) guidelines using calibration curve ( $\mathrm{n}=10)$ by residual standard deviation of $y$-intercepts of regression lines method, using formula $D L=3.3$ (residual standard deviation of $y$-intercepts of regression lines)/the slope of the calibration curve and $\mathrm{QL}=10$ (residual standard deviation of $\mathrm{y}$-intercepts of regression lines)/the slope of the calibration curve. IP is Indian Pharmacopoeia and EP/BP is European/British Pharmacopoeia 


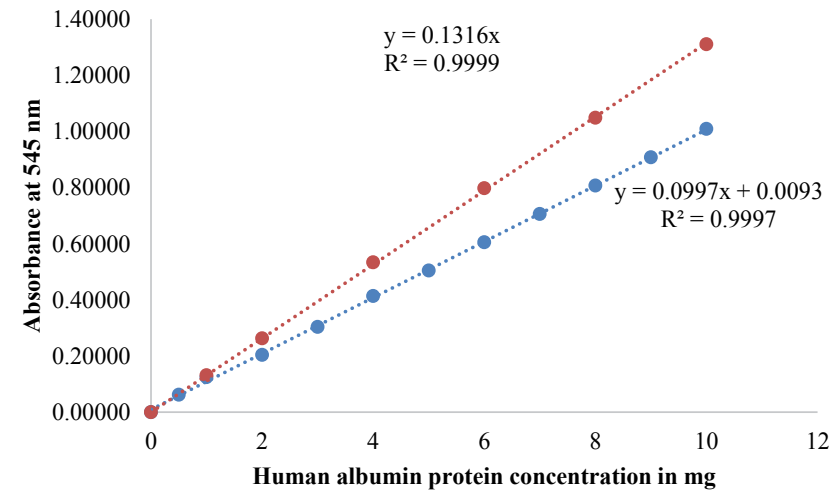

Fig. 1: Specific standard graph of both biuret methods used for calculation of LOD and LOQ

Standard concentrations between 1.0 to $10.0 \mathrm{mg} / \mathrm{ml}$ were used to plot standard curve for European/British Pharmacopoeial biuret method $(\bullet)$, and concentrations between 0.5 to $10 \mathrm{mg} / \mathrm{ml}$ were used to plot standard curve for Indian Pharmacopoeial biuret method $(\bullet)$

\section{Acknowledgments:}

The authors thank the Ministry of Health and Family Welfare, Government of India for providing the testing facility. Authors also thank and gratefully acknowledge the support of all laboratory staff.

\section{REFERENCES}

1. Global Specifications: The Example of Capreomycin -
Pharmacopoeial Standards. (WHO Drug Information Vol. 28, No. 4, 2014). Available from: http://apps.who.int/ medicinedocs/documents/s21722en/s21722en.pdf.

2. WHO good practices for pharmaceutical quality control laboratories. Available form: http://www.who.int/medicines/ areas/quality_safety/quality_assurance/Goodpractices PharmaceuticalQualityControlLaboratoriesTRS957Annex1. pdf.

3. The Gazette of India. Ministry of Health \& Family Welfare, Department of Health and Family Welfare (G.S.R. 908 (E) New Delhi, 22nd December, 2014). Available from: http://nib. gov.in/Gazette\%20notification_20032015.pdf.

4. Indian Pharmacopoeia. Vol. 1. New Delhi: Controller of Publication, Indian Pharmacopoeia Commission (IPC); 2014. p. 120.

5. British Pharmacopoeia. Vol. IV. London: HMSO Publication; 2017.

6. European Pharmacopoeia. 9th ed. Strasbourg: Council of Europe; 2007.

7. Prasad JP, Madhu Y, Mandan A, Garg P, Prakash A, Singh V, et al. Comparative study of two ELISA kits for estimation of antibodies to hepatitis B virus in human normal immunoglobulin and specific immunoglobulin intended for intravenous or intramuscular use. Indian J Clin Biochem 2016:32(2);243-5.

8. Prasad JP, Madhu Y, Singh S, Soni GR, Agnihotri N, Singh V, et al. Study of twenty preparations of human albumin solution which failed in quality control testing due to elevated sodium content, a poor internal quality control at manufacturing unit. Biologicals 2016:44;591-5. 